\title{
New frontiers in fertility preservation: a hypothesis on fertility optimization in men with hypergonadotrophic hypogonadism
}

\author{
Amin S. Herati, Taylor P. Kohn, Borna Kassiri \\ Department of Urology, The James Buchanan Brady Urological Institute, Johns Hopkins University School of Medicine, Baltimore, MD, USA \\ Contributions: (I) Conception and design: All authors; (II) Administrative support: AS Herati; (III) Provision of study material or patients: All authors; \\ (IV) Collection and assembly of data: All authors; (V) Data analysis and interpretation: All authors; (VI) Manuscript writing: All authors; (VII) Final \\ approval of manuscript: All authors. \\ Correspondence to: Amin S. Herati, MD. Department of Urology, The James Buchanan Brady Urological Institute, Johns Hopkins University School \\ of Medicine, Baltimore, MD 21287, USA. Email: aherati1@jhmi.edu.
}

\begin{abstract}
Strategies exist that can mitigate the risk of causing iatrogenic infertility when men require testosterone replacement therapy (TRT). This article reviews the current medical therapies that preserve spermatogenesis when TRT is indicated. Furthermore, we highlight the re-emerging concept of hypothalamic-pituitary-gonadal (HPG) axis reset in hypergonadotrophic, hypogonadal infertile men who are planning sperm retrieval procedures. Finally, we present our hypothesis for a novel protocol to optimize hypergonadotrophic hypogonadal men before sperm extraction surgeries hormonally.
\end{abstract}

Keywords: Male fertility; testosterone; hormonal therapy; non-obstructive azoospermia; testosterone therapy; Klinefelter syndrome

Submitted Aug 28, 2019. Accepted for publication Dec 24, 2019.

doi: $10.21037 /$ tau.2019.12.39

View this article at: http://dx.doi.org/10.21037/tau.2019.12.39

\section{Introduction}

Hypogonadism is defined by the Endocrine Society as a testosterone level $<300 \mathrm{ng} / \mathrm{dL}$ and is accompanied by associated symptoms, such as low energy and impaired libido (1). Testosterone therapy (TRT) is an effective treatment option that ameliorates symptoms of hypogonadism. Exogenous testosterone, however, can impair spermatogenesis by disrupting the hypothalamicpituitary-gonadal (HPG) axis. This adverse effect makes testosterone therapy challenging in men who wish to have children. The Endocrine Society recommends against TRT in men planning fertility in the near term (1).

Fortunately, strategies exist that can mitigate the risk of developing infertility associated with TRT. Some therapeutic strategies may even enhance the fertility potential of men with certain diagnoses. This article reviews the current medical therapies that preserve spermatogenesis when TRT is indicated, highlights the re-emerging concept of HPG axis reset in hypergonadotrophic, hypogonadal infertile men planning sperm retrieval procedures, and presents our hypothesis for a novel protocol in the optimization of hypergonadotrophic hypogonadal infertile men.

\section{Methods}

A literature review was performed in MEDLINE using the terms infertility, hypogonadism, testosterone, luteinizing hormone, and follicle stimulating hormone. Both basic and clinical studies were included.

\section{Physiology of the HPG axis}

Male fertility and proper functioning of the HPG axis are closely intertwined. Spermatogenesis depends on the pulsatile release of gonadotropins, follicle stimulating hormone (FSH), and luteinizing hormone (LH), from the pituitary, and their action on their cells in the testis. FSH signals to FSH receptors (FSHR) on Sertoli cells 
to initiate spermatogenesis, whereas $\mathrm{LH}$ signals to $\mathrm{LH}$ receptors (LHR) on Leydig cells to produce intratesticular testosterone (2). The qualitative and quantitative integrity of these receptors plays an equally significant role in the regulation of spermatogenesis. Unsurprisingly, inactivating mutations of the FSHR and LHR results in impaired fertility $(3,4)$. However, gonadotrophic overstimulation can also have a detrimental effect on spermatogenesis by downregulating the expression of LHR and FSHR (5). This effect may explain the clinical observations of Ross et al., who observed a reversible decline in sperm motility following high dose administration of selective estrogen receptor modulators (SERMs), which function by increasing the gonadotropin levels (6).

High intratesticular testosterone (ITT) levels maintain the spermatogenic process and prevent germ cell death (7). Low ITT levels result in an impaired blood-testis barrier permitting immune cells to enter the seminiferous tubules and attack autoantigenic germ cells [reviewed by Walker (8)]. Low intratesticular testosterone levels also block the conversion of round spermatids to elongating spermatogonia and prevent spermiation, leading to phagocytosis of spermatids by Sertoli cells $(8,9)$.

It is well established that exogenous testosterone therapy causes azoospermia in the majority of men (10). Exogenous testosterone's contraceptive effect occurs through its suppression of the HPG axis, preventing LH and FSH release and their respective gonadal functions (11). Studies examining the reproductive outcomes and rates of azoospermia development of various testosterone treatment modalities show less detrimental effects with testosterone patches [24\% rate of azoospermia (12)] compared to intramuscular injections of testosterone enanthate, which result in up to an $98 \%$ rate of combined azoospermia and oligozoospermia ( $\leq 3$ million/cc) after 1 year of therapy (13).

In a male contraceptive study, Coviello et al. followed seven healthy men with serum hormone assessments and percutaneous testicular aspirates to assess intratesticular hormone levels (14). They showed a 98\% suppression of $\mathrm{LH}, 97 \%$ suppression of FSH, and 93\% suppression of intratesticular androgenic bioactivity levels following weekly administrations of intramuscular testosterone enanthate (TE) $100 \mathrm{mg}$ with levonorgestrel over a 6-month treatment period compared to baseline. Levonorgestrel was administered to suppress the HPG axis further. One subject failed to suppress spermatogenesis with a nadir sperm count of $3.4 \mathrm{mill} / \mathrm{mL}$ despite a reduction in his ITT level from 1,607 to $29 \mathrm{nmol} / \mathrm{L}$ (98\% reduction). This study demonstrates the heterogeneity in TRT's contraceptive effect and the variability in intratesticular testosterone levels necessary for spermatogenesis to occur. Conversely, recovery of the HPG axis function following testosterone therapy cessation is possible but can take between 110 days and 2 years $(15,16)$.

\section{Strategies to preserve fertility when testosterone therapy cannot be stopped}

Hypogonadal men desiring fertility can become symptomatic beyond the capacity of current non-TRT medical therapies [see review by McBride and Coward (17) for non-TRT medical therapy]. Fertility can be maintained and potentially improved by the combination of exogenous testosterone therapy and adjunctive therapies to preserve spermatogenesis. Fertility data is available for the use of concomitant use of human chorionic gonadotropin (HCG) and aromatase inhibitor (AI) therapy with TRT. Below is evidence supporting the use of HCG, SERMs, and AI therapy.

\section{HCG}

HCG is a heterodimeric glycoprotein and an LH analog that binds to the $\mathrm{LH}$ receptor [also known as the luteinizing hormone/choriogonadotropin receptor (LHCGR)] to induce steroidogenesis. In studies comparing the intracellular effects of LH and HCG activation of the LHCGR $(18,19)$, HCG activation results in significantly higher cyclic adenosine-monophosphate (cAMP) levels, promoting anti-apoptotic and proliferative cell signaling events. However, there was no significant difference in testosterone production between the two gonadotropins, HCG and LH, in a murine Leydig cell model (18).

Due to its ability to stimulate Leydig cells independent of the HPG axis, HCG has been used as an adjunct therapy in men receiving testosterone supplementation who wish to preserve spermatogenesis. Coviello et al. (20) showed increasing doses of HCG administered concomitant with $200 \mathrm{mg}$ TE intramuscular injections in 29 healthy, and eugonadal men resulted in dose-dependent increases in the ITT levels. The men that were given TE and HCG 500 international units (IU) every other day had a $26 \%$ increase in their ITT levels over their baseline. Studies examining the ITT levels with high dose HCG are lacking.

In addition to maintaining ITT, low-dose HCG can preserve semen parameters in men on TRT. This was shown 
by Hsieh et al. (21) in a retrospective review of 26 men on testosterone replacement who were also given HCG 500 IU every other day. At 1 year, none of the patients became azoospermic, and no difference was observed in the semen volume, sperm density, or motility. This stability in semen parameters was not seen in an earlier study by Matsumoto and Bremmer (22), who followed four men administered $200 \mathrm{mg}$ TE and 5,000 IU three times weekly. Men on combination therapy with high-dose HCG showed a decrease in ejaculated sperm concentration from a mean $( \pm$ SEM) concentration of $79( \pm 7)$ million sperm/mL to $25( \pm 4)$ million sperm $/ \mathrm{mL}$ after 6 months of combination therapy.

\section{Selective estrogen receptor modulators and aromatase inbibitors}

SERMs and AI exert their action by inhibiting the negative feedback of estrogen on the hypothalamus and the anterior pituitary gland leading to increased LH and FSH production.

Among the SERMs, clomiphene citrate (CC) and tamoxifen citrate are commonly used for male patients with hypogonadal symptoms as monotherapy or in combination with HCG. To our knowledge, no studies are assessing the reproductive outcomes of SERMs given in conjunction with TRT. Therefore, it is unknown if central estrogen inhibition is enough to overcome the HPG suppression of TRT.

AI blocks the conversion of testosterone to estradiol by the enzyme aromatase. Commonly used AI for hypogonadism and male fertility include letrozole and anastrozole. While AI use is well established as monotherapy in hypogonadal men [reviewed by Tan et al. (23)], data supporting the use of AI and TRT is less rigorous. In a cohort of ten patients with Klinefelter syndrome, Mehta et al. (24) showed a 70\% surgical sperm retrieval rate in men given topical testosterone therapy with a goal testosterone of $>400 \mathrm{ng} / \mathrm{dL}$ combined with $1 \mathrm{mg}$ of anastrozole daily.

Few studies have examined the impact of combined testosterone therapy and AI on the HPG axis. Saki et al. (25) studied bone mineral density and HPG axis response in a four-arm sham-controlled study that compared control rats to orchiectomized rats that were given either given no additional therapy $v s$. TE intramuscular injections $v s$. $\mathrm{TE}$ and letrozole. The sham-control rats had LH values of $0.5 \pm 0.12 \mathrm{mIU} / \mathrm{mL}$, orchiectomized rats given TE had LH-suppression with $\mathrm{LH}$ values of $0.21 \pm 0.16 \mathrm{mIU} / \mathrm{mL}$, and orchiectomized rats given TE and letrozole had $\mathrm{LH}$ values of $0.45 \pm 0.45 \mathrm{mIU} / \mathrm{mL}$. These results suggest the potential for HPG stimulation with AI despite testosterone suppression. However, it is unclear if TRT+AI therapy can achieve enough HPG stimulation to maintain spermatogenesis.

\section{Nasal testosterone}

While it is known that testosterone pellets, intramuscular, and transdermal testosterone have detrimental effects on the HPG axis and spermatogenesis, newer modes of testosterone delivery may yield different results. Unique to nasal testosterone gel is its short half-life of only 10 100 minutes and its lack of pituitary gonadotropin suppression. This allows nasal testosterone to normalize androgen levels while maintaining baseline $\mathrm{LH}$ and FSH levels (26,27). Masterson et al. (28) explored nasal testosterone's effects on semen parameters as part of a phase IV clinical trial. Seventeen reproductive-aged men (mean age 35) received nasal testosterone three times daily. They had reproductive hormone measurements and semen analyses at baseline and intervals of 1 month, 3 months, and 6 months. Fifteen of the 17 enrolled men reached a 1-month follow-up, six reached a 3-month follow-up, and five reached a 6-month follow-up. The authors determined that after 1 month, 93\% (14/15) of the men achieved eugonadal testosterone levels (>300 ng/dL) with a median value of $423 \mathrm{ng} / \mathrm{dL}$. For the men who reached the 3 -month interval, the median total motile sperm count (TMSC) decreased from 37.5 to 24.8 million. However, at 6 months, the median TMSC increased to 32.5 million. Additionally, they observed no statistically significant change in LH and FSH levels throughout the trial (27). While this preliminary data is promising, more significant and longer-term studies are needed to confirm these findings.

\section{HPG axis reset-a new tool in our armamentarium?}

Among men with hypergonadotrophic, hypogonadal nonobstructive azoospermic (NOA) men, excess gonadotropin exposure carries the potential for desensitizing Leydig and Sertoli cells (5). This is believed to occur due to a decreased responsiveness of LH and FSH-responsive adenylyl cyclase following hyperstimulation. Increased cAMP catabolism due to FSH stimulated phosphodiesterase activity results in a refractory period for Sertoli cells $(29,30)$. Thus, a therapeutic dilemma with these men is the limited number 
Table 1 Demographics and the impact of HPG axis reset on perioperative hormone levels and microsurgical sperm recovery

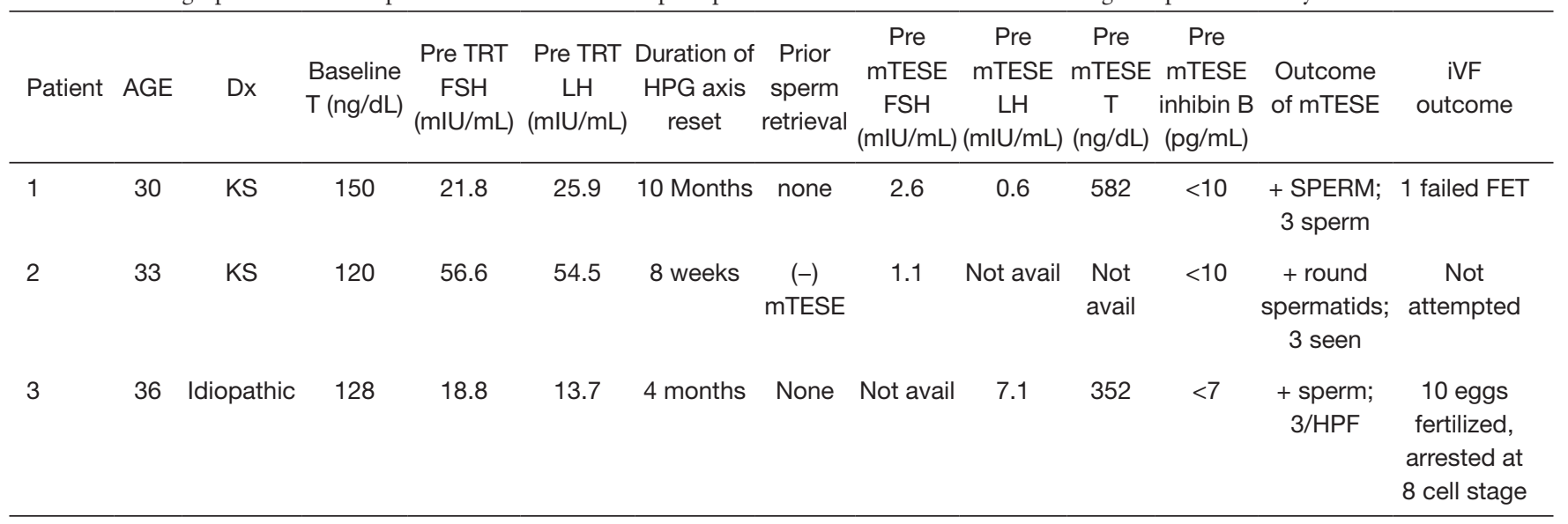

of options to improve the intratesticular testosterone before sperm search operations mixed with the potential for a detrimental effect of gonadotropins on Sertoli and Leydig cells. Emerging evidence has provided a potentially novel protocol for improving spermatogenesis in infertile men with hypergonadotrophic, hypogonadal NOA.

Among female infertility patients, controlled ovarian hyperstimulation $(\mathrm{COH})$ protocols exist to improve the response rate of women who respond poorly to in vitro fertilization (IVF) hormonal regimens, including the administration of estradiol patches and manipulation of the HPG axis with gonadotropins (31). COH protocols incorporate transdermal estradiol and GnRH-a in the luteal phase, followed by the administration of gonadotropins in the follicular phase to optimize the follicular hormonal milieu and antral follicle responsiveness. This protocol addresses the idea that individual follicles may have increased innate FSH receptor sensitivity, allowing for an increased response to a low rise in FSH in the early luteal phase. Thus, these follicles may demonstrate greater responsiveness to exogenous gonadotropins in the subsequent follicular phase leading to heterogeneity and unsynchronized follicular maturation before oocyte retrieval (32). The $\mathrm{COH}$ protocol utilizes early FSH suppression with estradiol and GNRH-a to counteract the innate FSH receptor sensitivity of individual follicles allowing for more synchronized follicular maturation and decreased heterogeneity after hyperstimulation with gonadotropins in the follicular phase (33). Clinically, this resulted in a significantly reduced number of canceled IVF cycles and improved considerably the number of oocytes retrieved and embryos transferred (31).
A similar protocol can be employed in men via HPG axis suppression and reactivation in a more controlled, pulsatile manner. In 2018, Hu et al. (34) investigated the effects of suppressing endogenous gonadotropins with GNRH $\alpha$ (Goserelin) and replacing them with exogenous gonadotropins in idiopathic NOA men. A total of 35 men were enrolled who had failed testicular sperm extraction (TESE). There were 10 men in a control group and 25 men in a group that received $150 \mathrm{IU}$ of human menopausal gonadotropins (hMG) twice weekly and 2,000 IU of HCG therapy once weekly after HPG suppression. Ultrasound assessed the testicular volume and hormone levels were followed. An inhibin rise was seen in 11 of 25 patients after 4 weeks on the gonadotropin therapy; however, this rise was sustained in only five patients at 20 weeks. Among these five men, one recovered sperm in their ejaculate at a concentration of $1.42 \times 10^{6} / \mathrm{mL}$ and another had sperm found on repeat TESE.

\section{Additional evidence for HPG axis reset: an independent case series}

Other case reports come from a review of the corresponding author's patients, including two patients with non-mosaic Klinefelter syndrome (47 XXY) and a third patient with idiopathic infertility who were all hypergonadotrophic, hypogonadal, and azoospermic on at least two semen analyses. In preparation for microsurgical testicular sperm extraction (microTESE), all three patients were symptomatic from their hypogonadism (Table 1). The two men with non-mosaic Klinefelter syndrome showed pretreatment testosterone $(\mathrm{ng} / \mathrm{dL})$ and $\mathrm{FSH}(\mathrm{mIU} / \mathrm{mL})$ levels 


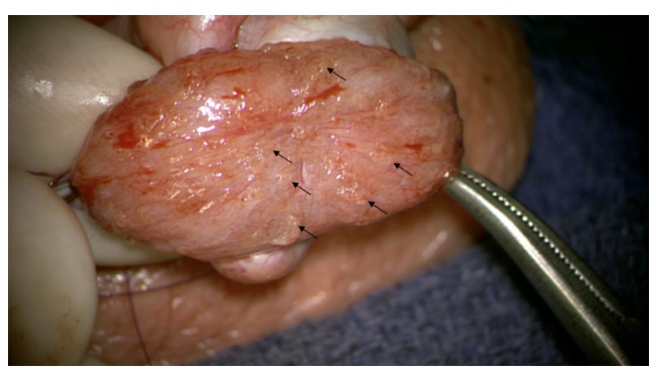

Figure 1 Microsurgical testicular sperm extraction in a male with 47XXY who underwent hypothalamic-pituitary-gonadal (HPG) axis reset. Black arrows indicate representative areas of dilated seminiferous tubules.

of $120-150 \mathrm{ng} / \mathrm{dL}$ and $21.8-56.6$, respectively. Following the administration of TE $200 \mathrm{mg} / \mathrm{mL}$ per week and $3000 \mathrm{IU}$ of HCG three times weekly for a minimum of 6 weeks, FSH levels for the 47XXY men decreased to $1.1-2.6 \mathrm{mIU} / \mathrm{mL}$ and testosterone levels rose to $>300 \mathrm{ng} / \mathrm{dL}$ in both patients. The third patient's pre- and post-treatment $\mathrm{LH}(\mathrm{mIU} / \mathrm{mL})$ levels decreased from 13.7 to 7.1. Pre-treatment FSH levels were $18.8 \mathrm{mIU} / \mathrm{mL}$; however, post-treatment FSH levels were not available. All patients were found to have sperm on microsurgical TESE (Figure 1). In vitro, fertilization was attempted for one patient with Klinefelter syndrome which resulted in an unsuccessful fresh embryo transfer despite high grade embryos (blastocyst stage - 2AA). From this IVF cycle, 30 oocytes were retrieved, 2 high-quality embryos were formed, and one was transferred. The second high-quality embryo was a cryopreserved pending repeat transfer. No IVF cycles have been attempted for the second or third patient.

One explanation for the successful sperm retrieval in these patients is the suppression of gonadotropins to more physiologic levels $(<10 \mathrm{mIU} / \mathrm{mL})$. Perhaps a further reduction of gonadotropins to undetectable levels may not have yielded the same outcome.

While this case series of three patients is small, it is the first report of TRT used to enhance the fertility potential of hypergonadotrophic, hypogonadal NOA men who previously had no effective strategy for hormonal optimization before their sperm retrieval. The observations made permit expression of a hypothesis that needs further investigation and validation.

\section{Conclusions}

Keeping men on TRT fertile has proven to be difficult for male fertility specialists. When the option of avoiding testosterone with alternative therapies, such as clomiphene citrate, aromatase inhibitors, and human chorionic gonadotropin, is not possible, some strategies can mitigate the negative impact of TRT on spermatogenesis. It is important to note that these therapies are not well established, possess limitations in their applicability, and carry side effects.

Novel methods of treating hypogonadal symptoms and keeping men fertile include the use of nasal testosterone and resetting the HPG axis with TRT and controlled administration of HCG. While preliminary results suggest that these methods may increase success for fertility treatments, more extensive research is needed to demonstrate the efficacy and safety of these therapies. The most recent evidence provides hope for the future of male fertility in patients that require TRT.

\section{Acknowledgments}

Funding: None.

\section{Footnote}

Provenance and Peer Review: This article was commissioned by the Guest Editors (Larry I. Lipshultz, Alexander W. Pastuszak) for the focused issue "Contemporary Issues and Controversies in Men's Health" published in Translational Andrology and Urology. The article was sent for external peer review organized by the Guest Editors and the editorial office.

Conflicts of Interest: The focused issue "Contemporary Issues and Controversies in Men's Health" was commissioned by the editorial office without any funding or sponsorship. The authors have no conflicts of interest to declare.

Ethical Statement: The authors are accountable for all aspects of the work in ensuring that questions related to the accuracy or integrity of any part of the work are appropriately investigated and resolved.

Open Access Statement: This is an Open Access article distributed in accordance with the Creative Commons Attribution-NonCommercial-NoDerivs 4.0 International License (CC BY-NC-ND 4.0), which permits the noncommercial replication and distribution of the article with the strict proviso that no changes or edits are made and 
the original work is properly cited (including links to both the formal publication through the relevant DOI and the license). See: https://creativecommons.org/licenses/by-ncnd/4.0/.

\section{References}

1. Bhasin S, Brito JP, Cunningham GR, et al. Testosterone therapy in men with hypogonadism: an endocrine society clinical practice guideline. J Clin Endocrinol Metab 2018;103:1715-44.

2. Crosnoe LE, Grober E, Ohl D, et al. Exogenous testosterone: a preventable cause of male infertility. Transl Androl Urol 2013;2:106-13.

3. Tapanainen JS, Aittomäki K, Min J, et al. Men homozygous for an inactivating mutation of the folliclestimulating hormone (FSH) receptor gene present variable suppression of spermatogenesis and fertility. Nat Genet 1997;15:205-6.

4. Lei ZM, Mishra S, Zou W, et al. Targeted disruption of luteinizing hormone/human chorionic gonadotropin receptor gene. Mol Endocrinol 2001;15:184-200.

5. Foresta C, Selice R, Moretti A, et al. Gonadotropin administration after gonadotropin-releasing-hormone agonist: a therapeutic option in severe testiculopathies. Fertil Steril 2009;92:1326-32.

6. Ross LS, Kandel GL, Prinz LM, et al. Clomiphene treatment of the idiopathic hypofertile male: high-dose, alternate-day therapy. Fertil Steril 1980;33:618-23.

7. Singh J, O'Neill C, Handelsman DJ. Induction of spermatogenesis by androgens in gonadotropin-deficient (hpg) mice. Endocrinology 1995;136:5311-21.

8. Walker WH. Spermatogenesis 2011;1:116-20.

9. Holdcraft RW, Braun RE. Androgen receptor function is required in Sertoli cells for the terminal differentiation of haploid spermatids. Development 2004;131:459-67.

10. Turek PJ, Williams RH, Gilbaugh JH. The reversibility of anabolic steroid-induced azoospermia. J Urol 1995;153:1628-30.

11. Liu PY, Swerdloff RS, Anawalt BD. Determinants of the rate and extent of spermatogenic suppression during hormonal male contraception: an integrated analysis. J Clin Endocrinol Metab 2008;93:1774-83.

12. Gonzalo IT, Swerdloff RS, Nelson AL. Levonorgestrel implants (Norplant II) for male contraception clinical trials: combination with transdermal and injectable testosterone. J Clin Endocrinol Metab 2002;87:3562-72.

13. Page ST, Amory JK, Bremner WJ. Advances in male contraception. Endocr Rev 2008;29:465-93.

14. Coviello AD, Bremner WJ, Matsumoto AM. Intratesticular testosterone concentrations comparable with serum levels are not sufficient to maintain normal sperm production in men receiving a hormonal contraceptive regimen. J Androl 2004;25:931-8.

15. Contraceptive efficacy of testosterone-induced azoospermia in normal men. World Health Organization Task Force on methods for the regulation of male fertility. Lancet 1990;336:955-9.

16. Anderson RA, Wu FC. Comparison between testosterone enanthate-induced azoospermia and oligozoospermia in a male contraceptive study. II. Pharmacokinetics and pharmacodynamics of once weekly administration of testosterone enanthate. J Clin Endocrinol Metab 1996;81:896-901.

17. McBride JA, Coward RM. Recovery of spermatogenesis following testosterone replacement therapy or anabolicandrogenic steroid use. Asian J Androl 2016;18:373-80.

18. Riccetti L, De Pascali F, Gilioli L, et al. Human LH and hCG stimulate differently the early signalling pathways but result in equal testosterone synthesis in mouse Leydig cells in vitro. Reprod Biol Endocrinol 2017;15:2 .

19. Casarini L, Lispi M, Longobardi S, et al. LH and hCG action on the same receptor results in quantitatively and qualitatively different intracellular signalling. PLoS One 2012;7:e46682.

20. Coviello AD, Matsumoto AM, Bremner WJ, et al. Low-dose human chorionic gonadotropin maintains intratesticular testosterone in normal men with testosterone-induced gonadotropin suppression. J Clin Endocrinol Metab 2005;90:2595-602.

21. Hsieh TC, Pastuszak AW, Hwang K, et al. Concomitant intramuscular human chorionic gonadotropin preserves spermatogenesis in men undergoing testosterone replacement therapy. J Urol 2013;189:647-50.

22. Matsumoto AM, Bremmer WJ. Stimulation of sperm production by human chorionic gonadotropin after prolonged gonadotropin suppression in normal men. J Androl 1985;6:137-43.

23. Tan RB, Guay AT, Hellstrom WJ. Clinical Use of Aromatase Inhibitors in Adult Males. Sex Med Rev 2014;2:79-90.

24. Mehta A, Bolyakov A, Roosma J, et al. Successful testicular sperm retrieval in adolescents with Klinefelter syndrome treated with at least 1 year of topical testosterone and aromatase inhibitor. Fertil Steril 2013;100:970-4.

25. Saki F, Kasaee SR, Sadeghian F, et al. The effect of 
testosterone itself and in combination with letrozole on bone mineral density in male rats. J Bone Miner Metab 2019;37:668-75.

26. Mattern, C, Hoffman C, Morley JE, et al. Testosterone supplementation for hypogonadal men by the nasal route. Aging Male 2008;11:171-8.

27. Rogol AD, Tkachenko N, Bryson N. "Natesto" ${ }^{\mathrm{TM}}$ ", a novel testosterone nasal gel, normalizes androgen levels in hypogonadal men. Andrology 2016;4:46-54.

28. Masterson T, Molina M, Ibrahim E. Natesto Effects on Reproductive Hormones and Semen Parameters: Results from an Ongoing Single-center, Investigator-initiated Phase IV Clinical Trial. Eur Urol Focus 2018;4:333-5.

29. Conti M, Toscano MV, Petrelli L. Involvement of phosphodiesterase in the refractoriness of the Sertoli cell. Endocrinology 1983;113:1845-53.

30. Sánchez-Yagüe J, Hipkin RW, Ascoli M. Biochemical properties of the agonist-induced desensitization of the follicle-stimulating hormone and luteinizing hormone/ chorionic gonadotropin-responsive adenylyl cyclase in

Cite this article as: Herati AS, Kohn TP, Kassiri B. New frontiers in fertility preservation: a hypothesis on fertility optimization in men with hypergonadotrophic hypogonadism. Transl Androl Urol 2020;9(Suppl 2):S171-S177. doi: 10.21037/ tau.2019.12.39 cells expressing the recombinant gonadotropin receptors. Endocrinology 1993;132:1007-16.

31. Dragisic KG, Davis OK, Fasouliotis SJ, et al. Use of a luteal estradiol patch and a gonadotropin-releasing hormone antagonist suppression protocol before gonadotropin stimulation for in vitro fertilization in poor responders. Fertil Steril 2005;84:1023-6.

32. Klein NA, Battaglia DE, Fujimoto VY et al. Reproductive aging: accelerated ovarian follicular development associated with monotropic follicle-stimulating hormone rise in older women. J Clin Endocrinol Metab 1996;81:1038-45.

33. Fanchin R, Salomon L, Castelo-Branco A, et al. Luteal estradiol pre-treatment coordinates follicular growth during controlled ovarian hyperstimulation with GNRH antagonists. Hum Reprod 2003;18:2698-703.

34. Hu X, Ding Z, Hong Z, et al. Spermatogenesis improved by suppressing the high level of endogenous gonadotropins in idiopathic non-obstructive azoospermia: a case control pilot study. Reprod Biol Endocrinol 2018;16:91. 